\title{
Mass-timber Construction in Australia: Is CLT the only answer?
}

\author{
Robert L. McGavin, ${ }^{\mathrm{a}, *}$ Tony Dakin, ${ }^{\mathrm{a}}$ and Jon Shanks ${ }^{\mathrm{b}}$ \\ Wood-based mass-panels (WBMP) are emerging as an attractive \\ construction product for large-scale residential and commercial \\ construction. Australia is following the lead of Europe and North America \\ with several recent projects being completed using predominately cross- \\ laminated timber panels (CLT). These sawn timber-based panels offer \\ some key advantages to the construction and sawmilling industry. \\ However, veneer-based mass-panel (VBMP) systems could offer \\ additional benefits including the more efficient use of the available forest \\ resources to produce WBMPs that have equivalent to superior \\ performance to CLT. Research to confirm the expected technical viability \\ of veneer-based systems is required. VBMPs could provide a valuable \\ contribution, alongside CLT, to the Australian timber products market.
}

Keywords: Mass panel; CLT; Cross laminated timber; Veneer; Mass plywood; Timber construction

Contact information: a: Queensland Department of Agriculture and Fisheries, Horticulture and Forestry Science, Salisbury Research Facility, 50 Evans Road, Salisbury, Queensland 4107 Australia; b: TimberED Services, PO Box 8096, Hilton,WA 6163. jonshanks@timbered.com.au

*Corresponding author: Robbie.mcgavin@daf.qld.gov.au

\section{INTRODUCTION}

Over the past decade or so, timber has seen a resurgence in use in large-scale residential and commercial construction. This is both due to, and has led to, a rise in prominence of large-section engineered-wood-products (EWPs), in particular, wood-based mass-panels (WBMP). This renaissance has been led by technologists and entrepreneurs in Europe and North America, who have been the first to develop these EWP types and to adopt the mass-timber construction approach.

This approach has also gained momentum in Australia. Although still in its infancy, with the first modern mass-timber building constructed only in 2012, Australia has seen the construction of numerous high-profile mass-timber buildings using mainly imported cross-laminated timber (CLT). In line with the increasing domestic demand for WBMPs, local manufacturing is currently being established, with the Australian industry predominately following the international precedent of CLT production.

With the product design of CLT incorporating the cross-lamination of a large number of sawn boards, superior mechanical properties and improved dimensional stability results compared to its constituent material. This product type therefore provides an attractive opportunity for sawmillers to absorb large volumes of sawn timber that does not meet the quality requirements of profitable target products with current large market share (i.e. structural framing). With this 'fall-down' product comprising up to $50 \%$ of total production and with limited capacity to even recover the production costs in most existing markets, new markets such as CLT manufacture that can absorb some of the fall-down product are needed to maintain sawmill profitability. 
However, Australia is traditionally a net importer of forest products, and the current plantation forest estate is expected to remain reasonably stable at around 2 million hectares. Therefore, for Australia to get the most benefit from the growing demand for sustainable, low embodied energy building products, alternative and more efficient approaches to using the available local forest resources should be considered to supply the growing market from locally manufactured products. Essentially, this requires processes that enable more highvalue volume to be recovered from the existing forest resources, as well as products that better utilize the recovered volumes and qualities.

There are several processing methods available for log conversion in addition to sawmilling. Rotary peeling has an extensive history that includes the manufacture of panel products such as plywood. Rotary peeling has long demonstrated its potential to recover a much higher proportion of log volume, which can be attributed in large part to the avoidance of waste associated with saw cuts and the geometric efficiencies of peeling in the round. While traditionally well suited to larger diameter logs, new technologies, including spindleless lathes, enable small diameter logs to be peeled with volume recoveries up to double that of modern sawing systems. This is illustrated in Fig. 1 showing the conversion of a $\sim 250 \mathrm{~mm}$ diameter $\log$.

Aside from increased volume recovery, the peeling process has advantages in better managing the quality variation that results from processing logs that contain highly variable wood properties along the radius (e.g. fast-grown plantation logs). This is also illustrated in Fig. 1, with the red coloring indicating lower quality juvenile wood and blue indicating the higher quality outer wood. When the log is sawn, resulting timber sections contain a range of properties (shades of red and blue), which can negatively influence performance, usability, and value. In contrast, when the same log is rotary peeled, each resulting veneer sheet is removed from a similar radial position within the log; therefore, each sheet contains reasonably consistent wood properties (i.e. same color in Fig. 1). This facilitates efficient feedstock segregation and therefore efficient product manufacture as the veneer qualities can be placed within the final product so that the properties are evenly balanced within the product, and also positioned for maximum structural and aesthetic advantage. Through rotary peeling, more of the higher quality wood (indicated by blue coloring) is recovered. A large volume of this higher value wood is lost during sawing with the conversion of a round $\log$ to square boards (Fig. 1).

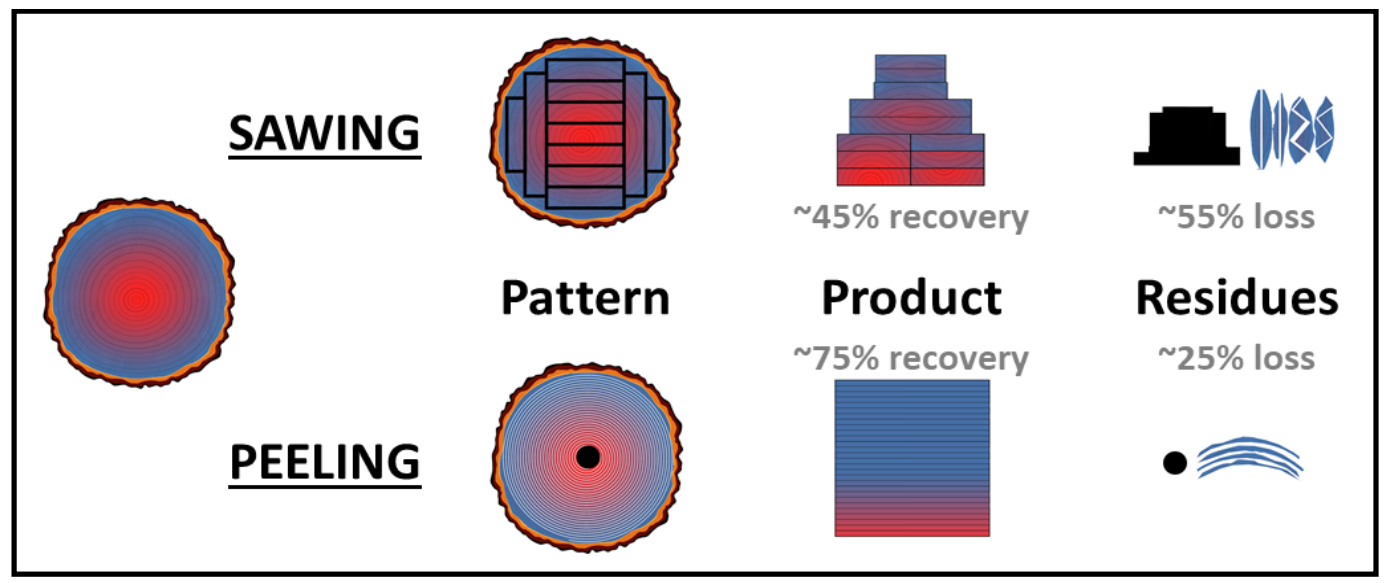

Fig. 1. Small log processing comparing product recovery from sawing and rotary peeling 
With rotary peeling having some clear processing and resource utilization advantages over sawmilling, this editorial will explore the comparative advantages and disadvantages of sawn board-based and veneer-based mass panels, providing clarity on research needs and opportunities to support the Australian industry in developing the domestic WBMP markets.

\section{MASS PANEL COMPARISON}

Many factors need to be considered when comparing the characteristics of veneerbased and sawn board-based mass-timber panels. This editorial discusses the technical performance of these panels across a range of performance requirements. Capital and production costs are not discussed.

\section{Durability}

Whilst the typical use for WBMPs is in an enclosed and weather-protected environment, there are robustness advantages and market opportunities for panel products with increased durability performance. Feedstock durability, preservative treatment and adhesive type all contribute to the durability of EWPs. While the majority of available timber resources are considered non-durable, using naturally durable timber species is possible for both sawn-board and veneer-based panels. However, these species are typically simpler to dry and adhere when in veneer rather than sawn board form. For the more commonly available non-durable species, veneer is significantly easier to penetrate with preservatives than sawn boards due to its small thickness and purely radial grain orientation. In addition to being simpler to adhere, the veneer industry typically uses phenolic-based adhesives, which have well-proven durability performance. Furthermore, veneer-based EWPs can be effectively protected against insect attack by the inclusion of a termiticide as part of the adhesive formulation, thus potentially eliminating the need for an additional treatment process during VBMP manufacture.

\section{Stability}

WBMPs are most often being used as high performance walls and floors in timber buildings. As such, it is essential that panels are dimensionally stable. Dimensional stability is typically achieved through cross-lamination. Inherently, CLT has high stability due to the cross-lamination. With the higher number of layers within VBMPs, opportunities for more optimized cross-lamination exist to maximize the benefits of structural performance and stability. While the increased wood layers in VBMPs offers several advantages, it does require higher total amount of adhesive compared to CLT.

\section{Structure}

The structural performance of WBMPs is influenced by the quality of feedstock used in production, the positioning within the panel cross-section, and the grain direction. The importance of different structural properties of the panel depend on the specific application in which the panel is used. Veneer-based EWPs generally have improved strength properties as compared to sawn board EWPs made from similar density and stiffness feedstock due to improved defect randomization and reinforcing from adjacent veneers. With the higher number of layers within VBMPs compared to CLT, there are 
greater opportunities for a larger proportion of the panel cross-section to have grain orientations that contribute to higher strength and stiffness performance in out-of-plane bending applications, such as for floor panels. In the case of stability walls, design and resulting structural performance is typically governed by fastener performance. Along with the inherent strength of the connectors themselves, fastener performance will be influenced by the density of the WBMP which is typically higher in a veneer-based product than a sawn board-based product. Higher performing connections will save money on a construction project, not only by reducing the number of fasteners required, but also through the reduced site time associated with installing fewer fasteners. Even more significant is that by having higher performing connections, the approach to the structural design may change to allow for example, composite cores, and activation of more shear walls in a system allowing for higher loads and taller buildings.

\section{Envelope}

It is generally understood that both CLT and VBMPs perform well regarding 'airtightness', and that sufficient air-tightness can be achieved in a mass-timber structure with either CLT or VBMPs by taping the panel junctions. Acoustic and thermal performance of WBMPs is affected by density. The higher density of VBMP resulting from the manufacturing process is expected to improve acoustic performance and reduce thermal performance. However, improved structural performance leads to thinner wall panels which can allow for increased thickness of high-performance thermal products such as insulation, and specific acoustic detailing.

\section{Fire}

The Australian National Construction Code contains a deemed-to-satisfy solution for fire design, under which sawn board-based and veneer-based WBMP are considered to perform equally. This approach precludes the visual exposure of timber panels and limits the allowable building height. A performance-based design approach provides greatest flexibility in product use whilst achieving the required fire performance. Two material factors affect performance-based fire design: density of the product, and the adhesive type used. Currently, typical production techniques for VBMPs and CLT use phenolic resins and polyurethane (PUR) adhesives respectively. Phenolic resin significantly outperforms PUR in the event of fire, allowing for a simpler approach to fire design by considering charring of the bonded timber without delamination.

\section{Summary}

Given the burgeoning use of WBMP in large-scale construction in Australia, along with the finite availability of Australian grown timber resources, the volumetric and quality recovery benefits associated with rotary veneer processing of logs justify further research into the development of VBMP products. Additionally, the equivalent to superior performance anticipated from VBMPs, as compared to sawn board-based WBMPs, strongly supports this approach. Should such research confirm the expected technical viability of veneer-based systems, and should they be able to be produced economically, VBMPs could provide a valuable contribution, alongside CLT, to the Australian timber products market. 